\title{
Atributos químicos do solo e produção de Urochloa brizantha cv. Marandu
}

\section{Chemical attributes of soil and production of Urochloa brizantha cv. Marandu}

\section{Patricia Juana Colmán Ribelatto ${ }^{1 *}$, Aline Marques Genú ${ }^{2}$, Sebastião Brasil Campos Lustosa ${ }^{2}$ e Cristiano André Pott ${ }^{2}$}

\footnotetext{
${ }^{1}$ Universidad Nacional de Canindeyú. Salto del Guairá, Canindeyú, Paraguay.

${ }^{2}$ Universidade Estadual do Centro Oeste. Guarapuava, Paraná, Brasil.
}

\author{
*Autor para correspondência: \\ pj_tr4@hotmail.com \\ Conflitos de Interesse: \\ Os autores declaram não ter \\ conflito de interesse \\ Licença: \\ Artigo publicado em acceso aberto \\ sob uma licença Creative \\ Commons CC-BY \\ Histórico: \\ Recebido: 29/11/17; \\ Aceito: $01 / 07 / 19$ \\ Período de publicaçao: \\ Julho-Dezembro de 2019
}

\section{RESUMO}

No departamento de Canindeyú da região oriental do Paraguai a produção de leite constitui uma das principais formas de economia para os pequenos produtores agropecuários, porém, o uso de insumos agrícolas não é uma prática na produção de pastagens, geralmente em razão do alto custo envolvido nestas práticas, especialmente do uso de adubos. O objetivo deste trabalho foi caracterizar os atributos químicos de solos sob pastagem de capim-Marandu e determinar sua produtividade por efeito de diferentes adubações. $O$ estudo foi realizado em quatro áreas localizadas no distrito de Jasy Cañy. Para as avaliações dos atributos químicos foram realizadas coletas de solo antes da adubação, nas camadas 0-10 e $10-20 \mathrm{~cm}$, determinando-se os teores de $\mathrm{Ca}^{2+}$, $\mathrm{Mg}^{2+}, \mathrm{K}^{+}, \mathrm{P}$ disponível, saturação por bases, saturação por alumínio, acidez trocável, $\mathrm{Al}^{3+}, \mathrm{CTC}_{\mathrm{pH} 7,0}, \mathrm{pH} \mathrm{CaCl} 2$ e matéria orgânica. Para a avaliação da produção de matéria seca e altura do dossel foi utilizado o delineamento de blocos completos ao acaso e os tratamentos consistiram na testemunha, adubação nitrogenada $\left(100 \mathrm{~kg} \mathrm{ha}^{-1}\right)$ e adubação com NPK (100-40-80 kg ha-1). Com base nos resultados verificou-se que os solos são medianamente ácidos, com ausência de toxicidade por $\mathrm{Al}^{3+}$, boa saturação por bases,

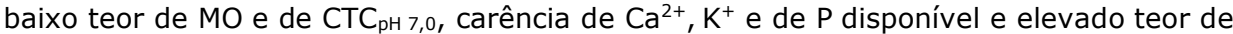
$\mathrm{Mg}^{2+}$ em relação ao $\mathrm{Ca}^{2+}$. A adubação com $\mathrm{N}$ ou NPK proporcionou aumento significativo na produção de matéria seca e na altura do dossel, sendo possível concluir que a adubação é fundamental para a produtividade da pastagem.

Palavras-chave: Pastagem, adubação, massa seca, altura dossel.

\section{ABSTRACT}

In the region of Canindeyú, milk production is one of the main forms of saving for small producers. However, the use of agricultural inputs is not practiced in the production of pastures, generally due to the lack of information on their importance, mainly fertilization. The objective of this work was to characterize the physical and chemical attributes of soils under Marandu grass and determine their productivity using different fertilizations. The study was conducted in four areas located in the district of Jasy Cañy. In order to evaluate the chemical attributes, soil samples were collected before fertilization in the $0-10 \mathrm{~cm}$ and $10-20 \mathrm{~cm}$ layers, using the levels of $\mathrm{Ca}^{2+}, \mathrm{Mg}^{2+}, \mathrm{K}^{+}$, extractable $\mathrm{P}$, base saturation, aluminum saturation, exchangeable acidity, $\mathrm{Al}^{3+}, \mathrm{CTC}_{\mathrm{pH} 7,0}$, pHCacl2 and organic matter as chemical indicators of soil quality. For dry matter production and height of the pasture, a complete randomized block design was used and the treatments consisted of control (without fertilization), nitrogen fertilization (100 kg $\mathrm{ha}^{-1}$ ) and fertilization with $\mathrm{N}-\mathrm{P}_{2} \mathrm{O}_{5}-\mathrm{K}_{2} \mathrm{O}\left(100-40-80 \mathrm{Kg} \mathrm{ha}{ }^{-1}\right)$. Based on the results the soils present a medium acidity, with no $\mathrm{Al}^{3+}$ toxicity, good base saturation, low $\mathrm{MO}$ and $\mathrm{CTC}_{\mathrm{pH}} 7.0$, lack of $\mathrm{Ca}^{2+}, \mathrm{K}^{+}$and extractable $\mathrm{P}$ and high $\mathrm{Mg}^{2+}$ content in relation to $\mathrm{Ca}^{2+}$. Fertilization with $\mathrm{N}$ and $\mathrm{N}-\mathrm{P}_{2} \mathrm{O}_{5}-\mathrm{K}_{2} \mathrm{O}$ provided significant increases in dry matter yield and height of Marandu grass presenting high responsive capacity, and it is possible to conclude that fertilization is the fundamental factor for pasture productivity.

Key words: Pasture, fertilizing, dry matter, height of pasture. 


\section{INTRODUÇÃO}

No departamento de Canindeyú, da região Oriental do Paraguai, especificamente no distrito de Jasy Cañy a produção de leite constitui uma das principais formas de economia para os pequenos produtores agrícolas, porém, o uso de insumos agrícolas, como adubos, calcários e outros não é praticado na produção de pastagens, devido ao seu alto custo, principalmente a adubação com NPK.

Considerando a baixa fertilidade da maioria dos solos tropicais e ao fato de que as gramíneas ( $\mathrm{C} 3 \mathrm{e}$ C4) possuem altas taxas de crescimento e sistemas radiculares que são capazes de extrair rapidamente nitrogênio, fósforo e potássio, a falta de reposição destes nutrientes provoca deficiência nutricional das plantas. Esta deficiência acarretará em uma série de perdas econômicas, pois, a redução do vigor da planta compromete sua rebrota e em longo prazo, provoca a degradação das pastagens (Peron e Evangelista, 2004).

Melhorar a fertilidade do solo é uma das principais ações a serem realizadas para aumentar a produtividade das pastagens e que permitem intensificar a sua utilização com maior taxa de lotação animal (Lugão, Rodrigues, Abrahão, Malheiros e Morais, 2003).

Dentre os macronutrientes, o nitrogênio, o fósforo e o potássio desempenham papel fundamental nos processos de crescimento e metabolismo das gramíneas forrageiras. O nitrogênio é considerado o principal nutriente para a produção de pastagens, uma vez que acelera a formação e o crescimento de novas folhas e aumenta o vigor de rebrota, melhorando a sua recuperação após a desfolha, resultando em maior produção das pastagens, sempre e quando não ocorra deficiência dos demais nutrientes, necessários para o desenvolvimento das plantas.

Contudo, a adubação das pastagens representa um grande investimento para o pecuarista e, portanto, entender a dinâmica de crescimento da pastagem em resposta a adubação para a utilização racional dos fertilizantes é de importância para obter elevada produtividade, por isso, torna-se importante determinar a influência exercida pela adubação nitrogenada ou pela adubação com nitrogênio, fósforo e potássio sobre a produtividade da pastagem de capim-Marandu.
Desta forma, o objetivo deste trabalho foi caracterizar os atributos químicos de solos sob pastagem de capim-Marandu e determinar sua produtividade utilizando diferentes adubações na região de Jasy Cañy - Paraguai.

\section{MATERIAL E MÉTODOS}

As avaliações do experimento iniciaram em novembro de 2015 e foram conduzidas em quatro propriedades de produtores de leite, localizadas na colônia Nova Aliança, distrito de Jasy Kañy pertencente ao departamento de Canindeyú, Paraguai.

Os solos da região são classificados como Typic Quartzipsamments (United States Departamento of Agriculture, 2014). O clima apresenta precipitação média anual de $1680 \mathrm{~mm}$ e temperatura média de $21,5^{\circ} \mathrm{C}$, o vento predominante da região é o nordeste (Dirección de Meteorología e Hidrología, 2014). De acordo com a classificação de KöppenGeiger o departamento de Canindeyú é considerado como $\mathrm{Cfa}$, clima subtropical, com temperatura média no mês mais frio inferior a $18^{\circ} \mathrm{C}$ e temperatura média no mês mais quente acima de $22^{\circ} \mathrm{C}$, verões quentes, geadas pouco frequentes e tendência de concentração das chuvas nos meses de verão, contudo sem estação seca definida.

As áreas estudadas estão ocupadas com pastagem de capim-Marandu implantadas há mais de 10 anos, submetido ao pastejo bovino continuo. Conforme a classificação de degradação de pastagens descrita por Dias-Filho (2011) a pastagem da região se encontra com nível de degradação considerado moderado, com baixa produtividade e presença de plantas daninhas, devido à falta de manejo.

A coleta de solo para análise química foi realizada em novembro de 2015, sendo coletadas amostras deformadas de solo. Para isto, dentro de cada área de estudo $\left(1500 \mathrm{~m}^{2}\right)$ foi selecionada uma área homogênea, tendo-se o cuidado de não realizar coletas próximo de cercas e de caminho dos animais. Cada área foi percorrida em zigue-zague em toda a sua extensão, retirando-se com uso de trado holandês, aleatoriamente, amostras simples em 10 pontos diferentes e, em cada ponto, em duas camadas $(0-10 \mathrm{~cm}$ e $10-20 \mathrm{~cm})$.

Logo, as amostras individuais de cada camada foram colocadas juntas em um balde plástico limpo, sendo bem misturadas, retirando-se em torno de 
$300 \mathrm{~g}$ de solo e colocadas em um saco plástico devidamente etiquetado, prontamente, as amostras foram enviadas ao laboratório para determinar os atributos químicos do solo: teores de $\mathrm{Ca}^{2+}, \mathrm{Mg}^{2+}, \mathrm{K}^{+}$ e $\mathrm{P}$ disponível, saturação por bases (V\%), saturação por cálcio $(\mathrm{Ca} \%)$, saturação por potássio $(\mathrm{K} \%)$, saturação por magnésio $(\mathrm{Mg} \%)$, saturação por alumínio $(\mathrm{m} \%)$, acidez trocável $\left(\mathrm{Al}^{3+}\right), \mathrm{CTC}, \mathrm{pH}$ e

matéria orgânica. $\mathrm{O} P$ e $\mathrm{K}^{+}$disponíveis foram obtidos pelo extrator Mehlich 1. Estas determinações químicas seguiram a metodologia descrita por EMBRAPA (2009).

Após obter os resultados das análises químicas do solo, cada propriedade foi delimitada em três parcelas de $500 \mathrm{~m}^{2}$ e no dia 16 de janeiro de 2016, realizou-se a adubação da pastagem, a mesma foi aplicada a lanço utilizando: adubação zero, adubação nitrogenada (100 kg ha-1) e adubação com N- $\mathrm{P}_{2} \mathrm{O}_{5}-\mathrm{K}_{2} \mathrm{O}\left(100-40-80 \mathrm{~kg} \mathrm{ha}^{-1}\right)$, constituindo três tratamentos (Tabela 1 ) utilizando delineamento experimental de blocos ao acaso com quatro repetições, totalizando 12 unidades experimentais. Como fonte de nitrogênio foi utilizada a ureia, para fósforo o superfosfato simples e para potássio o cloreto de potássio. As doses adotadas foram baseadas nas recomendações da Rede Oficial de Laboratórios de Análise de Solo e de Tecido Vegetal, 2004.

Tabela 1. Adubações utilizadas como tratamentos na área de estudo.

\begin{tabular}{ccc}
\hline Tratamentos & Adubo & Doses $\left(\mathbf{k g ~ h a}{ }^{-\mathbf{1}}\right)$ \\
\hline T1 & (Sem adubação) & 0 \\
T2 & $\mathrm{N}$ & 100 \\
T3 & $\mathrm{N}-\mathrm{P}_{2} \mathrm{O}_{5}-\mathrm{K}_{2} \mathrm{O}$ & $100-40-80$ \\
\hline
\end{tabular}

As avaliações da pastagem foram realizadas aos 60 , 100, 155 e 223 dias após a adubação, coletando-se amostras dentro das parcelas de cada tratamento para determinar matéria seca e altura do dossel.

A produção de massa seca por ocasião dos cortes foi determinada a partir da forragem verde colhida nos quadrados com $0,25 \mathrm{~m}^{2}(0,50 \mathrm{~m} \times 0,50 \mathrm{~m})$ de área útil (Gardner, 1986), tomadas em três pontos dentro de cada unidade experimental. A pastagem foi cortada rente ao solo com uma tesoura. Após, o material verde coletado foi embalado em sacos de papel e levados a estufa de circulação forçada de ar a temperatura de $60^{\circ} \mathrm{C}$, durante 72 horas, sendo posteriormente esse material pesado para determinar o peso da massa seca.

A altura do dossel foi determinada em 30 pontos aleatórios em toda a parcela, para cada unidade experimental, com o uso de um bastão graduado (sward stick) cujo marcador em acrílico transparente corre por uma régua e marca a distância entre o topo da superfície do pasto (lâmina foliar mais elevada) e a superfície do solo, conforme metodologia proposta por Barthram (1986).

Para as variáveis massa seca e altura de dossel os dados foram testados quanto à normalidade e homogeneidade, pelos testes Shapiro-Wilk e Bartlett, respectivamente, a 5\% de probabilidade de erro, e submetidos à análise de variância, utilizando o software ASSISTAT, e ao apresentar significância foi realizada a comparação de médias entre os tratamentos pelo teste de Tukey $(p \leq 0,05)$. Quanto aos atributos químicos não foi realizada análise estatística, somente a descrição das características químicas dos solos.

\section{RESULTADOS E DISCUSSÃO}

\section{Caracterização química dos solos sob pastagem de capim-Marandu}

Na Tabela 2 são apresentados os resultados das análises químicas do solo realizadas nas quatro áreas experimentais antes da adubação. $\mathrm{A}$ média dos valores de $\mathrm{pH}$ do solo variaram de 5,1 a 5,2 nas áreas analisadas, com pouca variabilidade entre as camadas resultando em solos ácidos em todas as profundidades conforme a classificação de Fatecha (2004). Solos ácidos são comuns em condições tropicais onde a precipitação pluviométrica com águas contendo $\mathrm{CO}_{2}$ provoca a lixiviação das bases das camadas superiores para as inferiores, sendo substituído nos coloides pelos íons $\mathrm{H}^{+}$(Ronquim, 2010). Outro fator importante sobre o qual são submetidos estes solos e que contribuem para sua acidificação, são as altas temperaturas que ocorrem durante $o$ ano inteiro. Estas aceleram o processo de intemperismo químico, que conforme Lepsch (2002) o aumento de $10^{\circ} \mathrm{C}$ na temperatura dobra a velocidade das reações químicas. Portanto, a intensidade de ação do intemperismo químico está diretamente proporcional ao aumento da temperatura. 
Tabela 2. Análise química de solo sob pastagem de capim-Marandu, Jasy Cañy-Canindeyú, Paraguai. 2016.

\begin{tabular}{|c|c|c|c|c|c|}
\hline \multirow{2}{*}{ Atributos do Solo } & \multicolumn{4}{|c|}{ Áreas } & \multirow{2}{*}{ Média } \\
\hline & 1 & 2 & 3 & 4 & \\
\hline \multicolumn{6}{|c|}{$0-10 \mathrm{~cm}$} \\
\hline $\mathrm{pH} \mathrm{CaCl} 2$ & 5,3 & 5,1 & 5,2 & 5,1 & 5,2 \\
\hline $\mathrm{MO}\left(\mathrm{g} \mathrm{dm}^{-3}\right)$ & 12,1 & 16,1 & 16,1 & 10,7 & 13,8 \\
\hline$P$ mehlich $\left(\mathrm{mg} \mathrm{dm}^{-3}\right)$ & 2,4 & 2,2 & 4,2 & 1,4 & 2,6 \\
\hline $\mathrm{Ca}\left(\mathrm{cmol}_{\mathrm{c}} \mathrm{dm}^{-3}\right)$ & 1,1 & 1,0 & 0,9 & 1,4 & 1,1 \\
\hline $\mathrm{Mg} \quad\left(\mathrm{cmol}_{\mathrm{c}} \mathrm{dm}^{-3}\right)$ & 2,8 & 2,0 & 2,2 & 2,0 & 2,3 \\
\hline $\mathrm{K}\left(\mathrm{cmol}_{\mathrm{c}} \mathrm{dm}^{-3}\right)$ & 0,15 & 0,11 & 0,15 & 0,12 & 0,13 \\
\hline $\mathrm{Al}\left(\mathrm{cmol}_{\mathrm{c}} \mathrm{dm}^{-3}\right)$ & 0,0 & 0,0 & 0,0 & 0,0 & 0,0 \\
\hline СТС pH 7,0 & 6,88 & 5,88 & 6,04 & 6,33 & 6,3 \\
\hline V $(\%)$ & 58,8 & 51,8 & 54,8 & 54,9 & 55,1 \\
\hline m (\%) & 0,0 & 0,0 & 0,0 & 0,0 & 0,0 \\
\hline $\mathrm{Ca}(\%)$ & 15,4 & 16,7 & 15,6 & 21,8 & 17,4 \\
\hline $\mathrm{Mg}(\%)$ & 41,3 & 33,3 & 36,8 & 31,3 & 35,7 \\
\hline K (\%) & 2,2 & 1,9 & 2,5 & 1,9 & 2,1 \\
\hline \multicolumn{6}{|c|}{$10-20 \mathrm{~cm}$} \\
\hline $\mathrm{pH} \mathrm{CaCl} 2$ & 5,2 & 5,0 & 5,2 & 5,1 & 5,1 \\
\hline $\mathrm{MO}\left(\mathrm{g} \mathrm{dm}^{-3}\right)$ & 6,7 & 12,1 & 9,4 & 8,1 & 9,1 \\
\hline $\mathrm{P}$ mehlich $\left(\mathrm{mg} \mathrm{dm}^{-3}\right)$ & 1,5 & 1,6 & 2,2 & 1,1 & 1,6 \\
\hline $\mathrm{Ca}\left(\mathrm{cmol}_{\mathrm{c}} \mathrm{dm}^{-3}\right)$ & 1,0 & 0,9 & 0,7 & 0,9 & 0,9 \\
\hline $\mathrm{Mg}\left(\mathrm{cmol}_{\mathrm{c}} \mathrm{dm}^{-3}\right)$ & 1,8 & 1,9 & 1,8 & 1,7 & 1,8 \\
\hline $\mathrm{K}\left(\mathrm{cmol}_{\mathrm{c}} \mathrm{dm}^{-3}\right)$ & 0,12 & 0,10 & 0,11 & 0,10 & 0,11 \\
\hline $\mathrm{Al}\left(\mathrm{cmol}_{\mathrm{c}} \mathrm{dm}^{-3}\right)$ & 0,0 & 0,0 & 0,0 & 0,0 & 0,0 \\
\hline СТC $\mathrm{pH} 7,0\left(\mathrm{cmol}_{\mathrm{c}} \mathrm{dm}^{-3}\right)$ & 5,51 & 5,59 & 4,86 & 5,27 & 5,3 \\
\hline V $(\%)$ & 51,2 & 51,2 & 52,7 & 51,2 & 51,6 \\
\hline m (\%) & 0,0 & 0,0 & 0,0 & 0,0 & 0,0 \\
\hline Ca $(\%)$ & 17,2 & 15,4 & 13,8 & 17,4 & 16 \\
\hline Mg (\%) & 31,8 & 34,0 & 36,8 & 31,9 & 33,6 \\
\hline K (\%) & 2,2 & 1,8 & 2,3 & 1,9 & 2,1 \\
\hline
\end{tabular}

Embora o pH tenha sido inferior a 5,3, os valores de $\mathrm{Al}^{3+}$ e $\mathrm{m} \%$ foram nulos o que indica que não existem problemas de toxicidade de $\mathrm{Al}^{3+}$ nas áreas analisadas. O teor médio de saturação por bases (V\%) para a profundidade de $0-10 \mathrm{~cm}$ foi de $55,1 \%$, e para $10-20 \mathrm{~cm}$ foi de $51,6 \%$. Estes resultados demonstram que a maioria dos solos possuem $\mathrm{V} \%$ elevado $(>50 \%)$, podendo ser classificados como eutróficos.

O teor de MO em geral variou de 6,7 a $16,1 \mathrm{~g} \mathrm{dm}^{-3}$, obtendo um teor médio maior na camada superficial de $0-10 \mathrm{~cm}$ com $13,8 \mathrm{~g} \mathrm{dm}^{3}$ em relação à camada de $10-20 \mathrm{~cm}$ com 9,1 g dm${ }^{3}$. Segundo Ronquim (2010) o teor de matéria orgânica em solos argilosos se consolida em torno de 25 a $30 \mathrm{~g} \mathrm{dm}^{-3} \mathrm{e}$ em solos de textura média ou arenosa em valores inferiores. Costa et al. (2000) mostram que a maior parte do sistema radicular das gramíneas encontra- se nos primeiros centímetros do solo os quais permitem maior concentração de matéria orgânica nas camadas superficiais.

Os valores de CTC tiveram média geral na camada de $0-10 \mathrm{~cm}$ de $6,3 \mathrm{cmol}_{\mathrm{c}} \mathrm{dm}^{-3}$ e na camada de 10 $20 \mathrm{~cm}$ de $5,3 \mathrm{cmol}_{\mathrm{c}} \mathrm{dm}^{-3}$, pode-se notar que os solos sob pastagem apresentaram CTC mais elevada na camada superficial onde o teor de MO também é maior, o que demonstra que a MO é relativa à CTC do solo. Os resultados são corroborados por Ronquim (2010) a qual menciona que a matéria orgânica pode representar mais de $80 \%$ do valor total da CTC.

Por outro lado, estes resultados também correspondem a solos característicos de alta percentagem de areia como são os solos da região amostrada. 
O teor médio de $\mathrm{Ca}^{2+}$ na camada de $0-10 \mathrm{~cm}$ foi de $1,1 \mathrm{cmol}_{\mathrm{c}} \mathrm{dm}^{-3}$ e na camada de $10-20 \mathrm{~cm}$ foi de 0,9 $\mathrm{cmol}_{\mathrm{c}} \mathrm{dm}^{-3}$, valores muito abaixo de $2,1 \mathrm{cmol}_{\mathrm{c}} \mathrm{dm}^{-3}$ (Comissão de química e fertilidade do solo, 2004). Nesta mesma linha seguem os dados de Ca\%, com valor médio geral de $16,6 \%$, considerado muito abaixo do adequado, uma vez que um solo com boas condições nutricionais para as culturas apresenta saturação de Ca entre $65-85 \%$. Em solo ácido com baixo teor de $\mathrm{Ca} \%$ o nutriente $\mathrm{Ca}^{2+}$ não se encontra disponível para a planta, podendo provocar deficiências nutricionais nas plantas.

Quanto aos valores de $\mathrm{Mg}^{2+}$ pode-se observar que ficou bem acima de $0,6 \mathrm{cmol}_{\mathrm{c}} \mathrm{dm}^{-3}$ (Comissão de química e fertilidade do solo, 2004), nível crítico deste nutriente. Também é possível verificar que os valores de $\mathrm{Mg} \%$ variaram de $31,3 \%$ a $41,3 \%$, confirmando excesso de $\mathrm{Mg}^{2+}$ no complexo de troca dos solos, considerando que saturações adequadas de $\mathrm{Mg}^{2+}$ segundo Kelling e Peters (2004) se encontram entre 6 e $12 \%$. Ainda, o alto teor de $\mathrm{Mg}^{2+}$ trocável presente nos solos desta região poderia estar impedindo a nutrição adequada de $\mathrm{Ca}^{2+}$ para as plantas.

O teor médio de $\mathrm{K}^{+}$para a região é de $0,13 \mathrm{cmol}_{\mathrm{c}}$ $\mathrm{dm}^{-3}$, valor inferior a $0,19 \mathrm{cmol}_{\mathrm{c}} \mathrm{dm}^{-3}$ que segundo Cubilla, Wendling, Eltz, Amado e Mielniczuk (2012) dá início à classe de teores elevados. Para os valores de $\mathrm{K} \%$, com uma média de 2,08\%, encontra-se no limite de boa disponibilidade de $\mathrm{K}^{+}$para as plantas e saturações entre 2 e $5 \%$ são avaliadas como apropriadas para que haja uma boa nutrição (Kelling \& Peters, 2004).

Os resultados de saturação das bases dão indícios de possível desequilíbrio entre elas. Tendo em conta que, teores mínimos de Ca\% (65 a 85\%), Mg\% (6 a $12 \%$ ) e de $\mathrm{K} \%$ (2 a 5\%) (Kelling e Peters, 2004) devem ser garantidos para que as culturas possam produzir bem, utilizando uma ampla faixa de variação dessas relações, considerando as necessidades nutricionais especificas de cada uma delas.

O teor médio de $P$ é de $2,6 \mathrm{mg} \mathrm{dm}^{-3}$ na camada de 0-10 cm e de $1,6 \mathrm{mg} \mathrm{dm}^{-3}$ para a camada de $10-20$ $\mathrm{cm}$. Os dados indicam que os solos apresentam disponibilidade muito baixa de $\mathrm{P}$ para essa região, considerando que Britos Benitez, Causarano Medina, Rasche Álvarez, Barreto Riquelme e Mendoza Duarte (2014) encontrou nível crítico de
$11,4 \mathrm{mg} \mathrm{dm}^{-3}$ de $\mathrm{P}$ nos solos do Paraguai. Estes resultados são muito similares aos encontrados no trabalho de monitoramento da fertilidade dos solos da Região Oriental do Paraguai, no qual Fatecha (2004) constatou em mais de $80 \%$ das análises de solos, que o $\mathrm{P}$ se encontrava em níveis baixos ou insuficientes para as plantas. $O$ alto grau de intemperismo e baixos teores de fósforo na forma disponível para as plantas são características muito específicas de solos tropicais (Rocha, Duda, Nascimento e Ribeiro, 2005), isto agregado ao fato da falta de hábito de fertilizar as pastagens agravam ainda mais a situação. De acordo com Santos et al. (2002) cerca de $70 \%$ dos solos cultivados com pastagens apresentam alguma limitação quanto à fertilidade, sendo que a baixa disponibilidade de fósforo é um dos fatores que limitam a produtividade de forrageiras em solos de regiões tropicais.

\section{Produção de capim-Marandu com diferentes adubações}

A produção de matéria seca da pastagem capimMarandu coletada aos 60, 100, 155 e 223 dias após a adubação é apresentada na Tabela 3. Aos 60 dias constata-se uma variação de $2154,8 \mathrm{~kg} \mathrm{MS} \mathrm{ha-1}$ a $7112,6 \mathrm{~kg}$ MS ha-1, indicando uma produção triplicada de MS para os tratamentos com adubação em relação à sem adubação. Ao mesmo tempo observa-se que a produção vai diminuindo ao longo do tempo, encontrando-se aos 223 dias uma variação de $1033,3 \mathrm{~kg} \mathrm{MS} \mathrm{ha-1}$ a 2768,5 kg MS ha1.

A análise de variância mostrou diferenças significativas $(P<0,05)$ dos tratamentos com adubações em relação à testemunha em todas as épocas analisadas. Estes resultados demostram que a adubação é determinante para a recuperação de pastagens e para conseguir maiores produções ao longo do tempo, uma vez observada à baixa produtividade da testemunha em relação aos tratamentos com adubações.

A baixa produção de forragem no tratamento testemunha está relacionada à condição de degradação em que se encontravam as pastagens analisadas, efeito de um manejo inadequado resultando em uma oferta restringida de forragem, e que consequentemente compromete de maneira importante o rendimento dos animais, tanto na produção de leite como no ganho de peso. Conforme 
Bonini et al. (2016) o manejo inadequado dos solos nas pastagens tem sido a principal limitação à sustentabilidade da pecuária de corte e de leite. Em outro estudo, Costa, Paulino, Magalhães, Rodigues e Santos (2009) mencionaram que as principais causas da degradação tem sido a queda da fertilidade do solo devido à falta de reposição e ou manutenção de nutrientes extraídos e a falta de manejo. Soares et al. (2005) corroboram que a falta de manejo da forragem é considerada fator fundamental que avalia às pastagens como pouco produtivas.

Tabela 3. Produção de matéria seca e altura do dossel do capim-Marandu após a adubação com $\mathrm{N}$ ou NPK. Jasy Cañy-Canindeyú, Paraguai. 2016.

\begin{tabular}{|c|c|c|c|c|}
\hline \multirow{2}{*}{ Tratamentos $\left(\mathbf{k g ~ h a} \mathbf{~}^{-1}\right)$} & \multicolumn{4}{|c|}{ Produção de matéria seca ( $k g$ MS ha-1) } \\
\hline & 60 dias & 100 dias & 155 dias & 223 dias \\
\hline 0 (testemunha) & $2154,8 b^{1}$ & 3119,7 b & $1989,1 \mathrm{~b}$ & $1033,3 \mathrm{~b}$ \\
\hline$N(100)$ & $6376,1 \mathrm{a}$ & $5230,1 \mathrm{a}$ & 4464,8 a & $2841,3 \mathrm{a}$ \\
\hline NPK (100-40-80) & $7112,6 \mathrm{a}$ & $6013,0 \mathrm{a}$ & $4719,4 \mathrm{a}$ & $2768,5 \mathrm{a}$ \\
\hline Média & 5214,5 & 4787,6 & 3724,4 & 2214,4 \\
\hline CV (\%) & 20.55 & 16,75 & 17,37 & 18,67 \\
\hline \multirow{2}{*}{ Tratamentos $\left(\mathrm{kg} \mathrm{ha}^{-1}\right)$} & \multicolumn{4}{|c|}{ Altura $(\mathrm{cm})$} \\
\hline & 60 dias & 100 dias & 155 dias & 223 dias \\
\hline 0 (testemunha) & $8,0 b^{1}$ & $14,9 \mathrm{~b}$ & $7,9 \mathrm{~b}$ & $6,7 \mathrm{~b}$ \\
\hline$N(100)$ & 33,6 a & $28,1 \mathrm{a}$ & $25,3 \mathrm{a}$ & $16,2 \mathrm{a}$ \\
\hline NPK (100-40-80) & 36,6 a & $27,1 \mathrm{a}$ & 25,6 a & $14,2 \mathrm{a}$ \\
\hline Média & 26,06 & 23,3 & 19,6 & 12,3 \\
\hline CV (\%) & 10,1 & 14,28 & 15,33 & 17,63 \\
\hline
\end{tabular}

${ }_{1}$ Médias seguidas pela mesma letra na coluna não diferem significativamente entre si pelo teste de Tukey $(P<0,05)$.

Mourão da Silva et al. (2015) mencionam que nos trópicos e subtrópicos as pastagens geralmente são estabelecidas em solos de baixa fertilidade ou com limitações severas para a produção de culturas. Nessas condições, e quando as exigências nutricionais das pastagens não são atendidas, não se pode esperar altos níveis de produção.

Não houve diferenças significativas para produção de MS acumulada entre os tratamentos com NPK e $\mathrm{N}$ em todas as épocas avaliadas. A falta de diferença entre os tratamentos $\mathrm{N}$ ou NPK podem estar atribuídos a que o nitrogênio era 0 nutriente mais limitante nas áreas analisadas e uma vez que este elemento foi suprido a aplicação do P e K não afetou a produção, pois de acordo com a "Lei do Mínimo ou de Liebig" a produção é limitada pelo nutriente que se encontra em menor disponibilidade, mesmo que todos os outros estejam disponíveis em quantidades adequadas (Malavolta, 1992).
Este aumento na disponibilidade de forragem é interessante, considerando que a alta produção de MS é importante para o pastejo bovino e, portanto, para o êxito da atividade pecuária. Por outro lado, estes resultados também ressaltam a importância do papel do $\mathrm{N}$ sobre a produção de matéria seca de pastagem. Este nutriente é essencial para a manutenção da produtividade e persistência da pastagem, e participa como principal constituinte das proteínas que atuam ativamente na síntese dos compostos orgânicos que formam a estrutura do vegetal (Santos et al., 2012).

Segundo Fagundes et al. (2005) devido a quantidade de $\mathrm{N}$ no solo, em muitas ocasiões, não atender as necessidades das gramíneas, estas podem ser mais exploradas em relação à produção e quando as forrageiras Urochloa são adubadas com $\mathrm{N}$, ocorrem modificações na taxa de acúmulo de matéria seca ao longo das estações do ano. 
Kluthcouski e Aidar (2003) mencionam que o N promove aumento imediato e visível na produção de forragem, isso acontece porque a quantidade de $\mathrm{N}$ disponibilizada pela matéria orgânica do solo, não tem sido suficiente para abastecer a necessidade das plantas forrageiras.

Ydoyaga et al. (2006) trabalhando com métodos de recuperação de pastagens de capim-braquiária (Urochloa decumbens Stapf), verificaram que a adubação nitrogenada propiciou aumento de 34\% na produção de massa seca na maior dose de N (100 $\mathrm{kg} \mathrm{ha}^{-1}$ ), neste estudo a adubação nitrogenada aos 60 dias promoveu aumento de $66,3 \%$ na produção de matéria seca com a mesma dose de $\mathrm{N}$, sendo observada alta capacidade responsiva do capimMarandu à adubação nitrogenada. A adubação nitrogenada afeta positivamente $\mathrm{o}$ rendimento de forragem e as características morfogênicas e estruturais das gramíneas (Costa et al., 2016).

De acordo com Cecato et al. (2000) o nitrogênio induz processos metabólicos, os quais resultam em benefícios acentuados na produção de matéria seca e energia para as gramíneas, promovendo um crescimento diferenciado de órgãos e sistemas.

De forma distinta aos resultados observados neste trabalho para $K$ e $P$, os quais não apresentaram efeito na produção e altura do capim-Marandu, Viana Porto et al. (2012) encontraram que a eficiência de utilização do fósforo pelo capimMarandu foi crescente até a dose máxima avaliada (150 kg de $\mathrm{P}_{2} \mathrm{O}_{5}$ ha $^{-1}$ ) e Lima, Fidelis e Costa (2007) observaram produção de $3.865 \mathrm{~kg} \mathrm{ha}^{-1} \mathrm{MS}$ aos 75 dias após a semeadura ao trabalhar com doses e fontes de fósforo no capim-Marandu, em ambos os casos, os autores atribuem tal resposta a deficiência natural deste elemento nos solos avaliados.

Quanto aos dados referentes à altura do dossel do capim-Marandu (Tabela 3) a análise de variância demostrou diferenças significativas dos tratamentos com adubações em relação à testemunha.

Aos 60 dias, a média do tratamento com adubação nitrogenada proporcionou um aumento de $76,2 \%$ e a adubação com NPK $78,2 \%$ em relação ao tratamento controle, os valores obtidos neste estudo são superiores aos encontrados por Silva Filho et al. (2014) que ao avaliarem a pastagem de capim-Marandu encontraram que a média das doses 250 e $350 \mathrm{~kg} \mathrm{ha}^{-1}$ de $\mathrm{N}$, proporcionaram $14,07 \%$ de acréscimo na altura em relação à testemunha.

Estes resultados explicam-se devido ao fato do $\mathrm{N}$ encontra-se em maior disponibilidade no solo e, consequentemente, para a planta. Segundo Alexandrino et al. (2003) este nutriente atua na zona de divisão celular, estimulando a maior produção de células e influenciando positivamente no alongamento foliar. Barbero et al. (2009) menciona que os fertilizantes nitrogenados aumentam significativamente a altura colaborando desta maneira para o desenvolvimento e produção das forrageiras. Benett et al. (2009) também encontraram que diferentes doses de fósforo aumentaram a produção de massa seca e altura da pastagem de capim-Marandu.

\section{CONCLUSÕES}

De acordo com os atributos químicos analisados, os solos sob pastagem de capim-Marandu em Jasy Cañy, são de baixa fertilidade.

Em relação a adubação houve um aumento significativo tanto na matéria seca como na altura do dossel da pastagem capim-Marandu, sendo este um fator fundamental para a produtividade das pastagens. No entanto, não houve diferença significativa entre os tratamentos $\mathrm{N}$ ou NPK o que pode estar atribuído a que 0 nitrogênio era 0 nutriente mais limitante e uma vez que foi suprido a aplicação do P e K não fizeram diferença.

\section{REFERÊNCIAS BIBLIOGRÁFICAS}

Alexandrino, E., Nascimento Júnior, D. do, Regazzi, A.J., Mosquin, P.R., Rocha, F.C. e Sousa, D.P. (2003). Produção de massa seca e vigor de rebrotação de Brachiaria brizantha cv. Marandu submetida a diferentes doses de nitrogênio e frequência de cortes. Brazilian Journal of Veterinary Research and Animal Science, 40(2), 141-147.

Barbero, L.M., Cecato, U. e Lugão, S.M.B., Nogueira Gomes, J.A., Limão, V.A. e Basso, K.C. (2009). Produção de forragem e componentes morfológicos em pastagem de coastcross consorciada com amendoim forrageiro. Revista Brasileira de Zootecnia, 38(5), 788-795.

Barthram G.T. (1986). Experimental techniques: the HFRO sward stick. In: Hill farming research Organisation. Biennial Report. Edinburgh: HFRO, 30 p. 
Benett, C.G.S., Silva, K.S., Yamashita, O.M., Teixeira Filho, M.C.M., Garcia, C.M.P., de P., Nakayama, F.T e Buzetti, S. (2009). Produção de Brachiaria brizantha sob doses crescentes de fósforo. Rev. Omnia Exatas, 2(1),25-32.

Bonini, C. dos S., Lupatini, G.C., Andrighetto, C., Mateus, G.P., Heinrichs, R., Aranha, A.S.,...Meirelles, G.C. (2016). Produção de forragem e atributos químicos e físicos do solo em sistemas integrados de produção agropecuária. Pesquisa Agropecuária Brasileira, Brasília, 51(9), 1695-1698 DOI: 10.1590/S0100$204 \times 2016000900070$.

Britos Benítez, C.A., Causarano Medina, H.J., Rasche Álvarez, J.W., Barreto Riquelme, U.F., e Mendoza Duarte, F. (2014). Fertilización fosfatada de los principales cultivos bajo siembra directa mecanizada en la región Oriental del Paraguay. Investig. Agrar., 14(2), 87-92.

Cecato, U., Yuriko Yanaka, F., Brito Filho, M.R.T. de, dos Santos, G.T., do Canto, M.W., Onorato, W.M. e Peternelli, M. (2000). Influência da adubação nitrogenada e fosfatada na produção, na rebrota e no perfilhamento do capim-Marandu (Brachiaria brizantha [Hochst] Stapf. cv. Marandu. Acta Scientiarum, 22(3), 817-822.

Comissão de química e fertilidade do solo (RS/SC CQFS). (2004). Manual de adubação e de calagem para os Estados do Rio Grande do Sul e de Santa Catarina. 10. ed. Porto Alegre: Sociedade Brasileira de Ciência do Solo - Núcleo Regional Sul, pp. 400

Costa, O.V., Costa, L.M., Fontes, L.E.F., Araujo, Q.R., Ker, J.C., e Nacif, P.G.S. (2000). Cobertura do solo e degradação de pastagens em área de domínio de Chernossolos no sul da Bahia. Revista Brasileira de Ciência do Solo, 24(4), 843- 856.

Costa, K.A.P., Faquin, V., Oliveira, I.P. de, Severiano, E.C., e Oliveira, M.A. de. (2009). Doses e fontes de nitrogênio na nutrição mineral do capimMarandu. Cienc. Animal Bras., 10:115-123.

Costa, N.L., Paulino, V.T., Magalhães, J.A., Rodigues, B.H.N. e Santos, F.J.S. (2016). Eficiência do nitrogênio, produção de forragem e morfogênese do capim-massai sob adubação. Nucleus, 13(2), 173-182.
Cubilla, M.M.A., Wendling, A., Eltz, F.L.F., Amado, T.J.C. e Mielniczuk, J. (2012). Recomendaciones de fertilización para soja, trigo, maíz y girasol bajo el sistema de siembra directa en el Paraguay. Asunción: Cámara Paraguaya de Exportadores y Comercializadores de Cereales y Oleaginosas, 83 p.

Dias-Filho, M.B. (2011). Degradação de pastagens: processos, causas e estratégias de recuperação. 4 ed. Belen, Brasil.

Dirección de Meteorología e Hidrología - DINAC. (2014). Disponível em: http://www.meteorologia.gov.py/ Acesso em: 25/4/2017.

Empresa Brasileira de Pesquisa Agropecuária. Embrapa Solos. (2009). Manual de análises químicas de solos, plantas e fertilizantes. $2^{\circ}$ ed. Brasília: Embrapa Comunicação para transferência de Tecnologia, $697 \mathrm{p}$.

Fagundes, J.F., Dilermando M. da, Gomide, J.A., Nascimento Junior, D. do, Vitor, C.M.T., Morais, R.V. de...Martuscello, J.A. (2005). Acúmulo de forragem em pastos de Brachiaria decumbens adubados com nitrogênio. Pesquisa Agropecuária Brasileira, 40(4), 397-403.

Fatecha, D.A. (2004). Clasificación de la fertilidad, acidez activa $(\mathrm{pH})$ y necesidad de cal agrícola de los suelos de la región oriental del Paraguay. Tesis (Graduación como Ingeniero Agrónomo). San Lorenzo: Universidad Nacional de Asunción.

Gardner, A.L. (1986). Técnicas de pesquisa em pastagens e aplicabilidade de resultados em sistema de produção. Brasília: IICA/ Embrapa-CNPGL, 197 p.

Kelling, K.A. \& Peters, J.B. (2004). The advisability of using cation balance as a basis for fertilizer recommendations. Wisconsin Fertlizer, Aglime, \& Pest Management Conference Proceedings. Disponível em: http://www.soils. wisc.edu/extension/FAPM/ 2004proceedings/Kelling1.pdf Acesso em: $17 / 08 / 2016$.

Kluthcouski, J. e Aidar, H. (2003). Uso da integração lavoura-pecuária na recuperação de pastagens. In: Kluthcouski, J., Stone, L.F., Aidar, H. (Ed). Integração lavoura-pecuária. Santo Antônio de Goiás: EMBRAPA Arroz e Feijão, p. 185-223. 
Lepsch, I.F. (2002). Formação e conservação do solo. Oficina de Textos. São Paulo: EMBRAPA, 178 p.

Lima, S.O., Fidelis, R.R. e Costa, S.J. de (2007). Avaliação de fontes e doses de fósforo no estabelecimento de Brachiaria brizantha CV. Marandu no Sul do Tocantins. Pesquisa Agropecuária Tropical, Goiânia, 37(2):100-105.

Lugão, S.M.B., Rodrigues, L.R.A. de, Abrahão, J.J.S., Malheiros, E.B. e Morais, A., de. (2003). Acúmulo de forragem e eficiência de utilização do nitrogênio em pastagens de Panicum maximum Jacq. (acesso BRA-006998) adubadas com nitrogênio. Acta Scientiarum. Animal Sciences, 25(2),371-379.

Malavolta, E. (1992). ABC da análise de solos e folhas. São Paulo: Agronômica Ceres, 124 p.

Mourão da Silva, E., Carvalho Andrade, A., Magalhães, J.A., Nunes Rodrigues, B.H., Bitencourt Oliveira, A.B., Seixas Santos, F.J. de... Bezerra, E.E.A. (2015). Características morfogênicas da Brachiaria brizantha cv. Marandu submetida a doses de nitrogênio. Pubvet, 9(6),262-270.

Peron, A.J. e Evangelista, A.R. (2004). Degradação de pastagens em regiões de cerrado. Ciência e Agrotecnologia, 28(3):655-661.

Rede Oficial de Laboratórios de Análise de Solo e de Tecido Vegetal (ROLAS). (2004). Manual de abudação e calagem para os estados do Rio Grande do Sul e Santa Catarina. 10 ed. Porto Alegre, Brasil: Sociedade Brasileira de Ciencia de Solo. 400p.

Rocha, A.T. da, Duda, G.P., Nascimento, C.W.A. e Ribeiro, M.R. (2005). Fracionamento de fósforo e avaliação de extratores de P-disponível em solos da ilha de Fernando de Noronha. Revista Brasileira de Engenharia Agrícola e Ambiental, 9(2), 178-184.

Ronquim, C.C. (2010). Conceitos de fertilidade do solo e manejo adequado para as regiões tropicais. Campinas: Embrapa Monitoramento por Satélite.
Boletim de Pesquisa e Desenvolvimento, 8, $26 \mathrm{p}$.

Santos, M.R., Fonseca, D.M., Gomes, V.M., da Silva, S.P., Silva, G.P. e Castro, M.R. (2012). Correlações entre características morfogênicas e estruturais em pastos de capim-braquiária. Ciência Animal Brasileira, 13: 49-56.

Santos, I.P.A., Pinto J. C., Siqueira, J.O., Morais A.R. de e Santos, C.L. dos (2002). Influência do fósforo, micorriza e nitrogênio no conteúdo de minerais de Brachiaria brizantha e Arachis pintoi consorciados. Revista Brasileira de Zootecnia. 31(2): 605-616.

Silva Filho A, S; Mousquer, C.J., Castro, W.J.R., Siqueira, J.V.M., Oliveira, V.J. e Machado, R.J.T. (2014). Desenvolvimento de Brachiaria brizantha Cv. marandu submetido a diferentes doses de uréia. Revista Brasileira de Higiene e Sanidade Animal. $8(1), 172-188$.

Soares, A.B., Carvalho, P.C.F. de, Nabinger, C., Semmelmann, C., Trindade, J.K. da, Guerra, E.,...Frizzo, A. (2005). Produção animal e de forragem em pastagem nativa submetida a distintas ofertas de forragem. Ciência Rural, 35(5), 11481154.

United States Departamento of Agriculture - USDA (2014). Keys to Soil Taxonomy. 12th Ed. Washington : Soil Survey Natural Resources Conservation Service Staff

Viana Porto, E.M., Alves, D.D., Vitor, C.M.T., Gomes, V.M., da Silva, M.F. e Santos de Souza David, A.M.S. (2012). Rendimento forrageiro da Brachiaria brizantha cv. Marandu submetida a doses crescentes de fósforo. Scientia Agraria Paranaensis, 11(3), 25-34.

Ydoyaga, D.F., Lira, M.A. de, dos Santos, M.V.F., Dubeux Júnior, J.C.B., Silva, M. da C., dos Santos, V.F. e Fernandes, A. de P.M. (2006). Métodos de recuperação de pastagens de Brachiaria decumbens Stapf. no Agreste Pernambucano. Revista Brasileira de Zootecnia, Viçosa, 35(3), 699-705. 